\title{
Logros en la comprensión de temas de genética utilizando representaciones externas
}

\author{
Fernando Flores-Camacho iD \\ Instituto de Ciencias Aplicadas y Tecnología, Universidad Nacional Autónoma de México, Circuito Exterior \\ S/N, Ciudad Universitaria, 04510, Mexico City.fernando.flores@icat.unam.mx
}

\section{Beatriz García-Rivera iD}

Instituto de Ciencias Aplicadas y Tecnología, Universidad Nacional Autónoma de México, Circuito Exterior S/N, Ciudad Universitaria, 04510,MexicoCity.beatrir:garcia@icat.unam.mx

\author{
Araceli Báez Islas iD \\ Instituto de Ciencias Aplicadas y Tecnología, Universidad Nacional Autónoma de México, Circuito Exterior \\ S/N, Ciudad Universitaria, 04510, Mexico City.baezi.araceli@gmail.com
}

\section{Leticia Gallegos-Cázares iD}

Instituto de Ciencias Aplicadas y Tecnología, Universidad Nacional Autónoma de México, Circuito Exterior S/N, Ciudad Universitaria,04510,MexicoCity.leticia.gallegos@icat.unam.mx

\section{Elena Calderón-Canales iD}

Instituto de Ciencias Aplicadas y Tecnología, Universidad Nacional Autónoma de México, Circuito Exterior S/N, Ciudad Universitaria, 04510, Mexico City.elena.calderon@icat.unam.mx

[Recibido: 3 junio 2019. Revisado: 10 febrero 2020. Aceptado: 22 mayo 2020]

Resumen: Este trabajo muestra el logro conceptual en genética de tres grupos de estudiantes de bachillerato $(\mathrm{N}=186)$ después de emplear tres secuencias didácticas con los mismos objetivos conceptuales y número de actividades, pero diferenciadas por el número y tipo de representaciones externas, así como en la organización de las actividades y en el uso de estas representaciones dentro del aula. Para identificar la comprensión conceptual y representacional lograda, cada estudiante respondió un cuestionario de 18 ítems. Los datos para el análisis se obtuvieron a partir de la calificación del cuestionario con una rúbrica y de un análisis ANOVA. Los resultados muestran que los alumnos del grupo donde el profesor diversificó las dinámicas de trabajo y se contó con más representaciones externas obtuvieron promedios más altos, dieron explicaciones escritas más completas y mostraron mayor precisión en sus representaciones simbólicas y gráficas. Las tres secuencias didácticas posibilitaron la comprensión conceptual de los estudiantes, pero aquella donde hubo una organización del grupo distinta, que permitió mayor variedad de tareas y uso de más representaciones, favoreció una mejor comprensión de los subtemas: células somáticas, células sexuales, mecanismos de herencia y alteraciones genéticas.

Palabras clave: Representaciones; Bachillerato; Genética; Aprendizaje; Didáctica.

\section{Achievements in the understanding of genetics topics using external representations}

\begin{abstract}
This work shows the conceptual achievement in genetics of three groups of high school students $(\mathrm{N}=186)$ after using three didactic sequences with the same conceptual objectives and number of activities, but differentiated by the number and type of external representations, as well as in the organization of activities and the use of these representations within the classroom. To identify the conceptual and representations understanding achieved, each student answered an 18-item questionnaire. The data for the analysis were obtained from the qualification of the questionnaire with a rubric and from an ANOVA analysis. The results show that the students of the group where the teacher diversified the work dynamics and had more external representations obtained higher averages, gave more complete written explanations and showed greater precision in their symbolic and graphic representations. The three didactic sequences made possible the conceptual understanding of the students, but the one where there was a different group organization, which allowed a greater variety of tasks and use of more representations, favored a better understanding of the subthemes: somatic cells, sex cells, mechanisms of inheritance and genetic alterations.
\end{abstract}

\author{
Revista Eureka sobre Enseñanza y Divulgación de las Ciencias \\ Universidad de Cádir. APAC-Eureka. ISSN: 1697-011X \\ http:/ / dx.doi.org/10.25267/Rev_Eureka_ensen_divulg_cienc.2020v17.i3.3101 \\ http:/ / reuredc.uca.es
}


Keywords: Representations; High school; Genetics; Learning; Didactic.

Para citar este artículo: Flores-Camacho, F., García-Rivera, B., Báez-Islas, A., Gallegos-Cázares, L., CalderónCanales, E. (2020) Logros en la comprensión de temas de genética utilizando representaciones externas. Revista Eureka sobre Enseñanza y Divulgación de las Ciencias 17(3), $3101 . \quad$ doi: 10.25267/Rev_Eureka_ensen_divulg_cienc.2020v17.i3.3101

\section{Introducción}

En general, se reconoce la necesidad de mejorar los procesos de enseñanza de las ciencias «... a fin de mejorar la participación de los ciudadanos en la adopción de decisiones relativas a la aplicación de los nuevos conocimientos...» (Organización de las Naciones Unidas para la Educación, la Ciencia y la Cultura [UNESCO] 2000, p.13). En particular, la enseñanza de la genética en el bachillerato, nivel en el que los alumnos se aproximan por primera vez de manera formal al tema, proporciona elementos indispensables para conocer y analizar, de manera informada, las investigaciones más recientes. Por ejemplo, el genoma humano, el uso de transgénicos y células troncales, que tienen impacto directo en aspectos cotidianos de la sociedad. Al respecto, diversos autores coinciden en lo importante de contar con una base conceptual adecuada, a la par que destacan el enorme reto que implica su aprendizaje (Banet y Ayuso 2000; Venville y Donovan 2007).

A pesar de lo deseable de esta situación, la investigación realizada en las últimas décadas (Caballero 2008; Figini y De Micheli 2005) muestra que los estudiantes evidencian dificultades para comprender los procesos y conceptos de genética. La naturaleza abstracta y compleja del tema, los diferentes niveles macro y micro que implica, su terminología o el contenido matemático en tareas mendelianas, son algunos de los factores que se atribuyen a esas dificultades (Knippels 2002).

Por otra parte, la investigación sobre el aprendizaje plantea nuevos enfoques que no se centran en la enseñanza de conceptos, sino en la importancia de la construcción e interpretación que los estudiantes hacen de las representaciones, con las que generan explicaciones de los fenómenos que observan y que forman parte de un complejo entramado que se da entre los conceptos y los diversos elementos involucrados en los fenómenos (Flores 2004; Gilbert 2008; Kozma y Russell 2005; Martí y Pozo 2000). Este enfoque representacional implica reconsiderar las formas de enseñanza a partir de la transformación de los objetivos de aprendizaje y de las situaciones didácticas, considerando que las representaciones son elementos centrales en los procesos cognitivos implicados en la construcción y transformación de estas en los sujetos y, en consecuencia, en sus procesos de aprendizaje (Prain y Tytler 2012, 2013; Wu y Puntambekar 2012). Dentro de esta perspectiva se han desarrollado propuestas que contemplan el uso de múltiples representaciones externas como estrategia para mejorar el aprendizaje de los alumnos.

Si bien, el tema de genética se ha investigado de manera relevante en distintos niveles educativos y con diferentes enfoques (Freidenreich, Duncan y Shea 2011; Garófalo, Chemes y Alonso 2016; Gericke y Wahlberg 2013), consideramos que el presente trabajo contribuye a su estudio al abordar el problema de su aprendizaje empleando distintos niveles y formas de representación externa en los procesos de enseñanza en el aula, e identificar si el enfoque representacional tiene potencialidades para mejorar la comprensión e integración de temas complejos para la ciencia escolar, como es el caso de la genética.

Por ello, el objetivo de esta investigación es analizar los logros de aprendizaje de los alumnos en tres condiciones distintas de trabajo en el aula, que consideran una misma trayectoria 
temática, pero difieren en las dinámicas de organización del grupo y en el tipo, cantidad y formas de uso de representaciones externas.

Nuestra hipótesis es que las representaciones externas que utiliza el docente para enseñar, al ser empleadas como elementos cognitivos que el alumno usa, reconstruye y explicita en distintas formas de organización e interacción con sus compañeros, contribuyen a una mejor comprensión de la genética. Bajo esa hipótesis, se analizaron tres grupos de estudiantes del último año de enseñanza media superior (bachillerato) de la Universidad Nacional Autónoma de México (UNAM), donde se aborda el tema de genética (Escuela Nacional Preparatoria [ENP] 1996). Cabe señalar que la UNAM es una institución de carácter público que, además de facultades, centros e institutos de investigación, tiene 14 escuelas en los que se imparte la educación media superior. Cada grupo trabajó el tema con su profesor de Biología V, quien definió la organización del grupo, los ejercicios y tareas para abordar el tema. Los profesores presentaron diferencias en el tipo, cantidad y formas de usar las representaciones externas en sus clases.

\section{Marco Teórico}

\section{Dificultades conceptuales para comprender la genética}

La genética es uno de los temas más tratados en la didáctica de la biología, pues es la base para entender otros temas como los mecanismos de evolución, la variabilidad de especies, o la síntesis de proteínas (Garvin y Stefani 1993) y, como ya se señaló, los avances alcanzados en este campo tienen repercusiones económicas y sociales.

Entre las principales dificultades para su aprendizaje, destacan:

1) La comprensión de la organización jerárquica de la información genética, que implica que el alumno transite entre niveles representacionales macro y microscópicos (Horwitz, Neumann y Schwartz 1996; Marbach-Ad y Stavy 2000). Por ejemplo, consideran a los genes como estructuras más grandes que los cromosomas (Caballero 2008; Iñiguez 2005).

2) Los fenómenos y procesos implicados no son evidentes (Kapteijn 1990), lo que lleva a los alumnos a realizar inferencias y analogías incorrectas y considerar solo aspectos del nivel macroscópico. Por ejemplo, consideran que fenotipo y genotipo actúan al mismo nivel.

3) La necesidad de reconocer, comprender e integrar tres modelos conceptuales: procesos celulares desde el modelo meiótico, diferentes patrones de herencia y, procesos moleculares (Stewart, Cartier y Passmore 2005). Por ejemplo, no relacionan la meiosis con la formación de los gametos, ni con la resolución de problemas de genética referidos a la transmisión y expresión de caracteres (Ibáñez y Martínez Aznar 2005; Lewis, Leach y Wood-Robinson 2000).

4) Como consecuencia de los puntos anteriores, la enseñanza de la genética se ha centrado en el determinismo del fenotipo a partir del genotipo, en una explicación direccional y desvinculada de las ideas inherentes a la genética moderna (Schneider, Della, Bologna, Benetti, Andrade y Meglhioratti 2011; Clément y Castéra 2013).

\section{Representaciones externas como estrategias para la enseñanza}

Las representaciones externas comprenden todo elemento icónico o simbólico con el que se denota lo representado. Para diSessa (2002) son el pilar del pensamiento externo al sujeto, pues a partir de ellas, podrá analizar y entender los fenómenos representados. En la enseñanza de las ciencias son relevantes como elementos para el aprendizaje porque favorecen el análisis a través del razonamiento y elaboración de inferencias que se llevan a cabo a partir de alguna de sus formas de expresión. De esta forma, las representaciones externas funcionan como 
herramientas para comprender, pero también son evidencia de la comprensión de los estudiantes. Por ejemplo, en el caso específico de la biología, la representación gráfica de un cromosoma o las simulaciones donde se observa su formación a partir de la condensación del ADN, implican la posibilidad de hacer inferencias y razonamientos, determinados por su estructura y función representacional.

Las representaciones externas, como estrategias para la enseñanza, pueden contribuir a la dimensión epistemológica del proceso de aprendizaje, pues involucra dos aspectos: los epistémicos, donde la construcción de modelos y variables de las representaciones funcionan como elementos constrictores de los procesos cognitivos de los sujetos y, la dimensión semántica, donde se dota de significado a símbolos y herramientas simbólicas (símbolos, imágenes, esquemas, gráficos y dibujos). Las herramientas simbólicas son importantes en la construcción de las propias representaciones de los sujetos, ya que sirven para mostrar procesos, mecanismos y estructuras que no se pueden observar directamente (Prain y Tytler 2012).

Actualmente hay investigaciones que muestran cómo, el uso de las representaciones en la enseñanza de las ciencias contribuye al aprendizaje. Schnotz y Bannert (2003), reportan la influencia de las representaciones verbales y pictográficas en la estructura de los modelos mentales de los estudiantes. Los trabajos de Diez de Tancredi y Caballero (2004); Eilam (2013); Schonborn y Bogeholz (2013), destacan la influencia de las múltiples representaciones externas para ayudar a los alumnos a transitar entre los diferentes niveles representacionales de los procesos biológicos. Rotbain, Stavy y Marbach-Ad (2008) han mostrado que su uso ayuda a los estudiantes a comprender, por ejemplo, el proceso molecular de traducción de genes a proteínas.

Particularmente en genética, es común que los profesores usen representaciones externas (Diez de Tancredi y Caballero 2004), debido al tipo de contenidos abstractos y los niveles macro y micro implicados. Sin embargo, los docentes pocas veces están al tanto del importante papel que su uso pudiera tener en el aprendizaje, es decir, aunque saben que les son útiles, no necesariamente identifican la necesidad de promover de forma explícita el uso de representaciones externas como herramientas cognitivas que faciliten la comprensión, por ejemplo, mediante el análisis de diversas representaciones para generar inferencias e interpretaciones (Tsui y Treagust 2013).

Todos estos elementos dan cuenta de la importancia que tienen las representaciones externas en el aprendizaje, y destacan la necesidad de enmarcar el diseño de las actividades de enseñanza considerando también los recursos representacionales de los alumnos. Así, tomando estos elementos en consideración, se desarrolló la propuesta que se presenta a continuación, junto con el proceso de intervención realizado.

\section{Los procesos en clase}

Para conocer las implicaciones de las representaciones externas en la comprensión de los conceptos y representaciones que los estudiantes logran de la genética, se analizaron tres grupos que cursaban la materia de Biología V. En cada uno, el profesor correspondiente implementó una secuencia didáctica con distintas tareas y ejercicios que implicaban diversidad en la utilización de tipos y número de representaciones externas, lo que proporcionó variedad en las formas de enseñanza.

Las tres secuencias comparten una estructura básica en cuanto a los seis temas que abordaron: niveles de organización celular y de la información genética; ciclo celular; mitosis y meiosis; 
herencia mendeliana; herencia por alelos múltiples; alteraciones cromosómicas, génicas o puntuales. Cada secuencia contempló seis actividades, una por cada tema.

En la tabla 1 se enlistan las herramientas representacionales y estrategias empleadas por el docente en cada secuencia, como puede apreciarse, la secuencia I fue aplicada en el grupo 1 (G1) y, dependiendo del tema, utilizó lecturas, cuestionarios, ejercicios en el pizarrón o en el cuaderno, mapas conceptuales y/o explicaciones del profesor; en la secuencia II, aplicada en el grupo 2 (G2), se incorporaron más recursos en las actividades, como lecturas con más imágenes, cuadros comparativos, organizadores gráficos, y explicaciones del profesor; la secuencia III, correspondiente al grupo 3 (G3), tuvo más elementos representacionales en sus actividades, como lecturas con imágenes, animaciones, mapas conceptuales, resolución de problemas y una actividad experimental.

Tabla 1. Herramientas representacionales empleadas en cada secuencia didáctica.

\begin{tabular}{|c|c|c|}
\hline $\begin{array}{l}\text { Estrategia didáctica I } \\
\text { Grupo } 1(\mathrm{G} 1)\end{array}$ & $\begin{array}{c}\text { Estrategia didáctica II } \\
\text { Grupo } 2(\mathrm{G} 2)\end{array}$ & $\begin{array}{c}\text { Estrategia didáctica III } \\
\text { Grupo } 3(\mathrm{G} 3)\end{array}$ \\
\hline $\begin{array}{l}\text { Lectura de textos sin imágenes. } \\
\text { Explicaciones del profesor, con } \\
\text { apoyo de presentaciones } \\
\text { digitales con texto, } \\
\text { organizadores gráficos e } \\
\text { imágenes fijas. } \\
\text { Explicaciones del profesor, con } \\
\text { escritos, esquemas y mapas } \\
\text { conceptuales que hacía en el } \\
\text { pizarrón. } \\
\text { Resolución de cuestionarios, } \\
\text { ejercicios y organizadores } \\
\text { gráficos impresos. } \\
\text { Resolución de ejercicios con } \\
\text { piezas de foamy (etileno acetato } \\
\text { de vinilo) para representar } \\
\text { fenotipos. }\end{array}$ & $\begin{array}{l}\text { Lectura de textos con imágenes. } \\
\text { Explicaciones del profesor, con } \\
\text { apoyo de presentaciones digitales } \\
\text { con textos, organizadores gráficos, } \\
\text { fotografías e imágenes fijas. } \\
\text { Explicaciones del profesor, con } \\
\text { escritos, esquemas y mapas } \\
\text { conceptuales que hacía en el } \\
\text { pizarrón. } \\
\text { Resolución de cuestionarios, } \\
\text { ejercicios y organizadores gráficos } \\
\text { impresos. } \\
\text { Investigaciones en libros e internet } \\
\text { con generación de reporte escrito } \\
\text { con imágenes que representan los } \\
\text { conceptos. } \\
\text { Análisis de analogías con texto e } \\
\text { imágenes. } \\
\text { Trabajo con esquemas con } \\
\text { imágenes. } \\
\text { Trabajo con animaciones con } \\
\text { audio, texto e imágenes. }\end{array}$ & $\begin{array}{l}\text { Lectura de textos con imágenes } \\
\text { Explicaciones del profesor, con } \\
\text { apoyo de presentaciones digitales } \\
\text { con textos, imágenes y animaciones } \\
\text { con audio, texto e imágenes. } \\
\text { Explicaciones del profesor, con } \\
\text { escritos, dibujos, esquemas y mapas } \\
\text { conceptuales que hacía en el } \\
\text { pizarrón. } \\
\text { Resolución de cuestionarios, } \\
\text { ejercicios y organizadores gráficos } \\
\text { con imágenes, en formato digital. } \\
\text { Investigaciones en libros e internet } \\
\text { con generación de reporte escrito } \\
\text { con imágenes que representan los } \\
\text { conceptos. } \\
\text { Trabajo con simuladores para } \\
\text { resolución de ejercicios. } \\
\text { Realización de actividad } \\
\text { experimental en el laboratorio. } \\
\text { Resolución de cuestionarios } \\
\text { digitales interactivos con imágenes. } \\
\text { Resolución de ejercicios a través de } \\
\text { casos clínicos con esquemas. } \\
\text { Observación de videos. } \\
\text { Consultas en Internet de imágenes, } \\
\text { animaciones e información. }\end{array}$ \\
\hline
\end{tabular}

Los tres profesores que participaron son biólogos quienes después de concluir su formación disciplinar, se incorporaron a la práctica docente y tienen de 15 a 20 años de experiencia frente a grupo. Cada profesor implementó su secuencia con su grupo, de forma tal que cada secuencia se trabajó a lo largo de seis sesiones de dos horas para completar las seis actividades, en cada grupo el periodo de aplicación fue de un mes.

La Secuencia I (G1) se realizó en un laboratorio que contaba con pizarrón y mobiliario para trabajar en parejas. La Secuencia II (G2), en un salón con pupitres individuales, pizarrón, y proyector conectado a la computadora del profesor. La Secuencia III (G3), tanto en un salón con pupitres individuales, pizarrón, proyector conectado a la computadora del profesor, como 
en uno de los nuevos laboratorios del bachillerato de la UNAM (que cuentan con una computadora para el docente, computadoras para distintos equipos de alumnos, acceso a Internet, diversos recursos digitales y materiales para desarrollar prácticas experimentales).

La tabla 2 es un ejemplo de las diferencias en la forma en que los profesores organizaron a su grupo y las herramientas representacionales que emplearon. En este caso, se muestra la actividad 1 que aborda el tema Niveles de organización de la información genética.

Tabla 2. Descripción de los recursos representacionales empleados por los alumnos en la actividad 1, que abordó el tema Organización de la información genética.

\begin{tabular}{|c|c|c|}
\hline Secuencia didáctica I (G1) & Secuencia didáctica II (G2) & Secuencia didáctica III (G3) \\
\hline $\begin{array}{l}\text { Trabajo individual. Lectura de texto } \\
\text { sin imágenes, con información para } \\
\text { elaborar un glosario ilustrado de los } \\
\text { conceptos cromatina, ADN, bases } \\
\text { nitrogenadas, gen, cromosoma y } \\
\text { locus. } \\
\text { Trabajo en plenaria. Explicación del } \\
\text { profesor con presentación digital } \\
\text { con una imagen sobre los niveles de } \\
\text { organización. }\end{array}$ & $\begin{array}{l}\text { Trabajo individual. Lectura de texto } \\
\text { con imágenes, con información para } \\
\text { elaborar un glosario de los conceptos } \\
\text { cromatina, ADN, bases nitrogenadas, } \\
\text { gen, cromosoma y locus. } \\
\text { Trabajo en plenaria. Explicación del } \\
\text { profesor con presentación digital con } \\
\text { imágenes que representan los } \\
\text { conceptos analizados. } \\
\text { Trabajo individual. Uso de imágenes } \\
\text { impresas de los niveles de } \\
\text { organización, para su acomodo } \\
\text { jerárquico. } \\
\text { Trabajo individual. Elaboración de } \\
\text { mapa conceptual ilustrado, para } \\
\text { identificar las relaciones y jerarquías de } \\
\text { los conceptos del glosario. }\end{array}$ & $\begin{array}{l}\text { Trabajo en equipos. Lectura con } \\
\text { imágenes, con información para elaborar } \\
\text { un glosario ilustrado de los conceptos } \\
\text { cromatina, ADN, bases nitrogenadas, } \\
\text { gen, cromosoma y locus. } \\
\text { Trabajo en plenaria. Explicación del } \\
\text { profesor con presentación digital con } \\
\text { imágenes y analogías que representan los } \\
\text { conceptos analizados. } \\
\text { Trabajo en equipo. Revisión de } \\
\text { animación sobre los niveles de } \\
\text { organización. }\end{array}$ \\
\hline
\end{tabular}




\section{Metodología}

\section{Muestra}

Participaron 186 alumnos con edades entre los 17 y 19 años, quienes cursaban el último año de bachillerato, turno matutino. La muestra estuvo dividida de la siguiente forma: G1, 60 alumnos (45 mujeres y 15 hombres); G2, 60 alumnos (46 mujeres y 14 hombres), y G3, 66 alumnos (50 mujeres y 16 hombres). Los alumnos pertenecían a dos escuelas distintas de la ENP. Para toda la muestra fue la primera vez que el tema se abordó con esta profundidad conceptual, pues su antecedente se ubica en el primer año de la escuela secundaria (11 a 12 años de edad) donde su aprendizaje solo considera, en forma muy superficial, la importancia y función del ADN, cromosomas y genes.

\section{Instrumento}

Para conocer el logro conceptual de los alumnos, se aplicó un cuestionario con 18 ítems (coeficiente Alpha de Cronbach de 0.88), que los alumnos respondieron una semana después de haber concluido las actividades de las secuencias didácticas.

El diseño del instrumento estuvo orientado por la perspectiva de Integración de Conocimiento, esto es, tener la habilidad de generar ideas relevantes, así como conectar ideas para elaborar mejores explicaciones de un fenómeno determinado (Lee, Liu y Linn 2011). Los ítems demandaban a los alumnos responder mediante descripciones, explicaciones e interpretaciones escritas, así como la elaboración de representaciones como dibujos, esquemas de procesos o estructuras genéticas. Esto significa que implicaron demandas conceptuales y representacionales como, por ejemplo, representar y describir los niveles de organización de la información genética en diferentes tipos celulares, con la intención de que relacionaran sus dibujos y esquemas con las explicaciones que dieron. Cabe señalar que la estructura y organización del instrumento no era familiar para los alumnos de ninguno de los tres grupos, es decir, ningún estudiante había resuelto anteriormente un cuestionario con estas demandas, por lo que ninguno estuvo favorecido para resolverlo. Los aspectos conceptuales y de representación gráfica que cada ítem abordó se muestran en la tabla 3, donde puede notarse que, de manera general, su resolución implicaba la integración de los diferentes temas que se abordaron en la secuencia.

Tabla 3. Estructura de los ítems del cuestionario.

\begin{tabular}{|c|l|}
\hline Ítem & \multicolumn{1}{c|}{ Estructura de los ítems } \\
\hline 1 & Solicita descripción escrita de porqué se expresan determinadas características en un bebé humano. \\
\hline 2 & $\begin{array}{l}\text { Solicita se indique y justifique dónde se encuentra la información que se hereda. Incluye incisos para } \\
\text { seleccionar y luego justificar la selección. }\end{array}$ \\
\hline 3,4 & $\begin{array}{l}\text { Solicitan representación gráfica y descripción escrita de cómo se organiza la información genética en } \\
\text { las células sexuales (espermatozoide y óvulo). }\end{array}$ \\
\hline 5 & $\begin{array}{l}\text { Indaga, mediante respuesta escrita, si considera diferencias en la información genética de todas las } \\
\text { células del cuerpo. }\end{array}$ \\
\hline 6 & $\begin{array}{l}\text { Solicita que, por medio de representaciones gráficas, describa la información genética de una célula } \\
\text { somática y una sexual. }\end{array}$ \\
\hline
\end{tabular}


Tabla 3. Continuación

\begin{tabular}{|c|l|}
\hline Ítem & \multicolumn{1}{c|}{ Estructura de los ítems } \\
\hline $7,8,9,10$ & $\begin{array}{l}\text { Corresponden a la solución de un problema de herencia mendeliana, con la característica del lóbulo } \\
\text { de las orejas a partir de conocer el fenotipo de los padres y abuelos: } \\
\text { El ítem } 7 \text { solicita representaciones gráficas que describan cómo considera se presenta la información } \\
\text { genética en el óvulo y en el espermatozoide de los padres. } \\
\text { El ítem } 8 \text { solicita una representación gráfica que describa cómo considera que se presenta la } \\
\text { información genética de las células del bebé de la pareja hipotética. } \\
\text { El ítem 9 solicita indique dónde se localiza la información genética para la expresión de la } \\
\text { característica del ejemplo (los lóbulos de la oreja). } \\
\text { El ítem 10 solicita las probabilidades de expresión de un determinado fenotipo en la progenie a } \\
\text { partir de los genotipos paternos. }\end{array}$ \\
\hline 11,12 & $\begin{array}{l}\text { Demandan las probabilidades de expresión del tipo sanguíneo, utilizando el mecanismo de alelos } \\
\text { múltiples, así como definir si esta característica tiene relación con la herencia de otras. }\end{array}$ \\
\hline 13,14 & $\begin{array}{l}\text { El ítem 13 pide descripción y representación gráfica del síndrome de Down; el ítem 14 indaga si se } \\
\text { reconoce influencia entre el sexo del progenitor y la herencia del síndrome de Down. }\end{array}$ \\
\hline 15,16 & $\begin{array}{l}\text { El ítem 15 solicita se indique qué tan posible es que distintos factores influyan en que se presente } \\
\text { una alteración genética en la descendencia; mientras que el ítem 16 pide descripción y representación } \\
\text { de una alteración genética. }\end{array}$ \\
\hline 17 & $\begin{array}{l}\text { Solicita explicación del porqué existe variabilidad genética entre hermanos. } \\
\text { Demanda la representación y ubicación de las estructuras en que se organiza la información } \\
\text { genética, de gametos y de una alteración genética. }\end{array}$ \\
\hline 18
\end{tabular}

Para determinar el nivel de integración de conocimiento alcanzado en las respuestas de los alumnos para cada ítem, se construyó una rúbrica, basada en la propuesta de Wilson (2005) con una escala determinada por niveles que van del 0 al 5 , misma que se validó con el modelo de crédito parcial de Rasch (programa Winstep). La tabla 4 muestra los criterios generales para asignar los niveles de integración. Los aspectos referentes al cuestionario, como su descripción detallada y validación, pueden consultarse en Flores-Camacho, García-Rivera, Báez-Islas y Gallegos-Cázares (2017).

Tabla 4. Criterios de la escala de calificación.

\begin{tabular}{|l|l|}
\hline $\begin{array}{l}\text { Niveles de Integración de } \\
\text { Conocimiento }\end{array}$ & Nivel y características de las respuestas a los ítems \\
\hline Vínculos complejos & $\begin{array}{l}\text { 5. Explicita tres o más conceptos e ideas relevantes y elabora dos o más } \\
\text { vínculos válidos entre ellas }\end{array}$ \\
\hline Vínculos totales & $\begin{array}{l}\text { 4. Explicita al menos dos conceptos e ideas relevantes y elabora un } \\
\text { vínculo válido entre dos ideas. }\end{array}$ \\
\hline Vínculos parciales & $\begin{array}{l}\text { 3. Explicita ideas o conceptos relevantes, pero no elabora } \\
\text { adecuadamente vínculos entre ellos. }\end{array}$ \\
\hline No hay Vínculos & 2. Explicita ideas no precisas y no relacionadas \\
\hline Irrelevante & 1. Contiene ideas irrelevantes al contexto científico \\
\hline No hay información & 0. No hay respuesta al ítem \\
\hline
\end{tabular}

Fuente: Adaptado de Wilson (2005). 


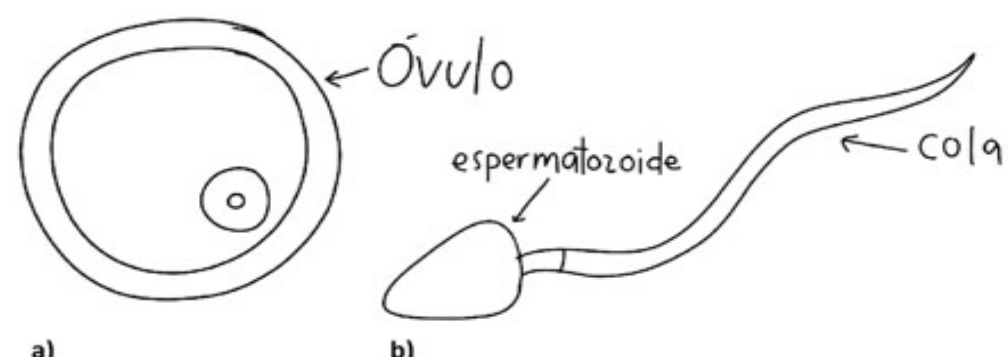

a)

b)

Figura 1. Alumno de G1: Representación de los gametos en nivel 2. Dibuja cómo son espermatozoide (a) y óvulo (b), menciona que tienen información genética.

Como ejemplo de la aplicación de la rúbrica, se muestran las respuestas y la asignación de nivel para los ítems 3 y 4, que contemplan respuestas relacionadas.

Nivel 1. No hace mención de que espermatozoide y óvulo son células sexuales, aunque dibuja su estructura externa. No relaciona conceptos ni representaciones con ningún nivel de organización de la información genética. No hace referencia a qué información genética aportan para la formación de un nuevo ser (figura 1).
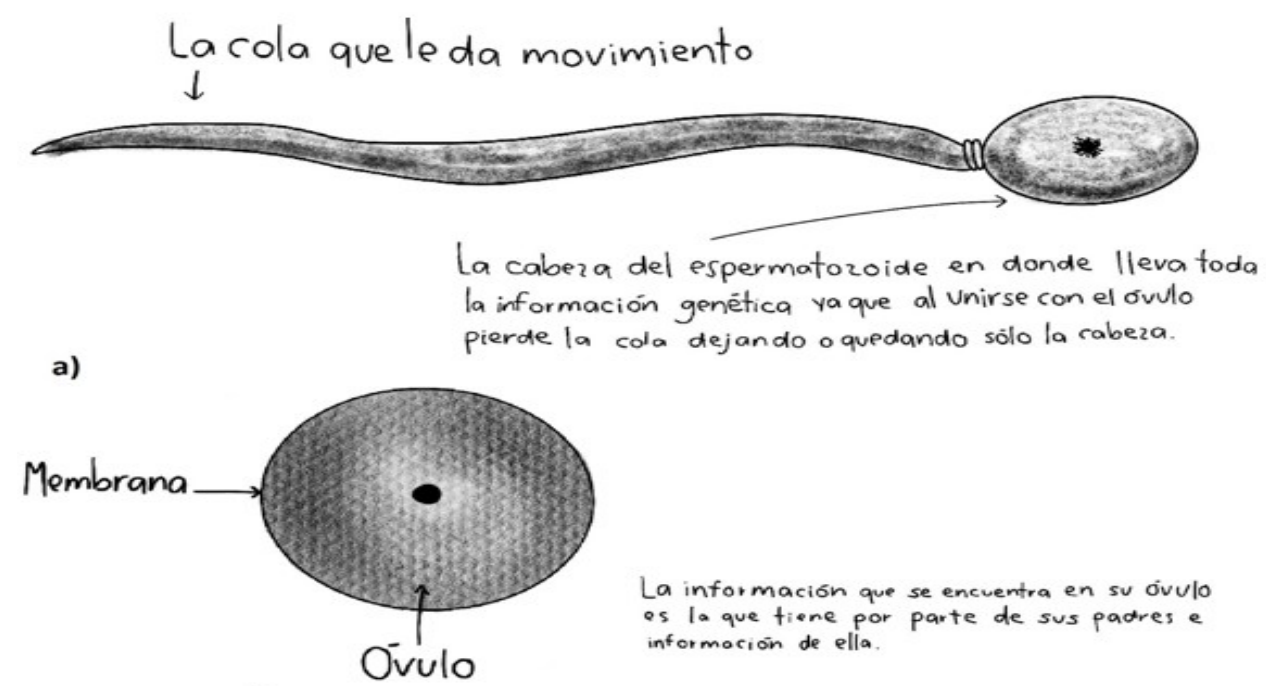

La información que se encuentra en su óvulo es la que tiene por parte de sus padres e

Es esférico de una informoción de ella.

b) medidao tamaño diminuto

Figura 2. Alumno de G1: Representación de los gametos en nivel 1. No distingue si hay información genética y cómo se organiza en óvulo (a) y espermatozoide (b).

Nivel 2. Reconoce que espermatozoide y óvulo son células sexuales y puede representar sus características generales, no detalla qué información genética presentan. No hace referencia a la organización de la información genética que aportan los gametos para la formación de un nuevo ser (figura 2).

Nivel 3. Reconoce que espermatozoide y óvulo son células sexuales con información genética, representa un solo nivel de organización (con las siglas $\mathrm{ADN}$, cromatina como hebras, cromosomas sexuales o alelos en forma de letras). Menciona que son las encargadas de aportar la información para la formación de un nuevo ser (figura 3). 

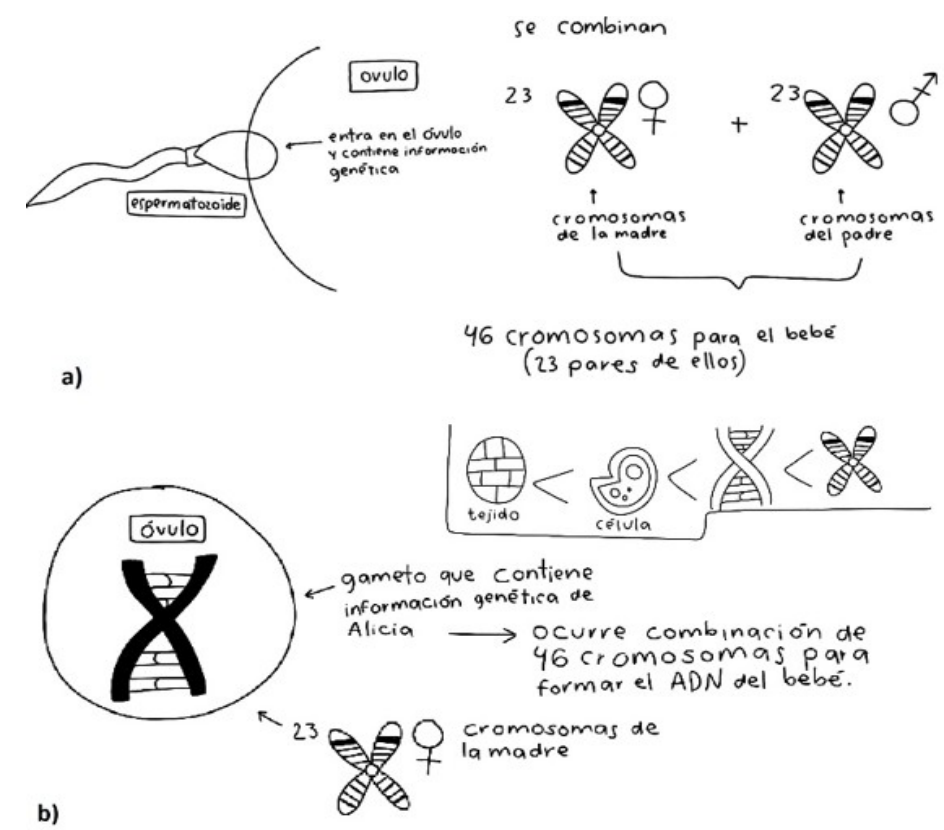

Figura 3. Alumno de G2: Representación de los gametos en el nivel 3, espermatozoide (a) y óvulo (b). Muestra información genética como cromosomas, de los que cada progenitor aporta 23; dibuja cómo son las células sexuales y menciona que tienen información genética.

Nivel 4. Además de lo descrito en nivel 3, indica que óvulo y espermatozoide participan en la fecundación y formación de un nuevo ser y que aportan información genética de cada padre. Considera a los gametos con cromosoma sexual, que simboliza como XX o XY, pero no indica cuántos cromosomas tienen en total (figura 4).
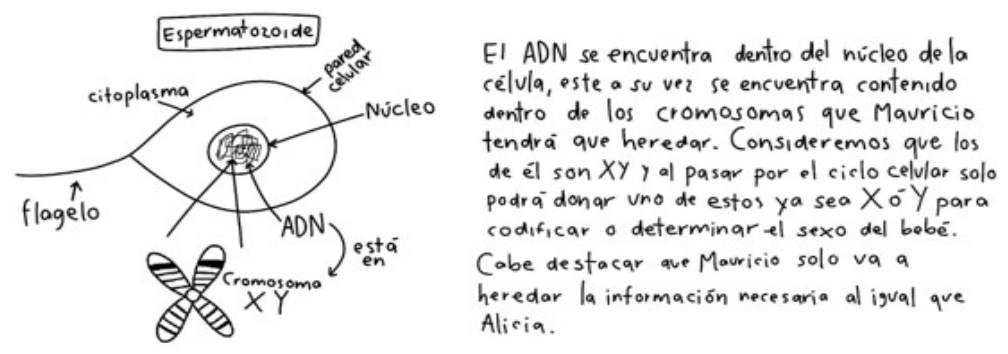

a)

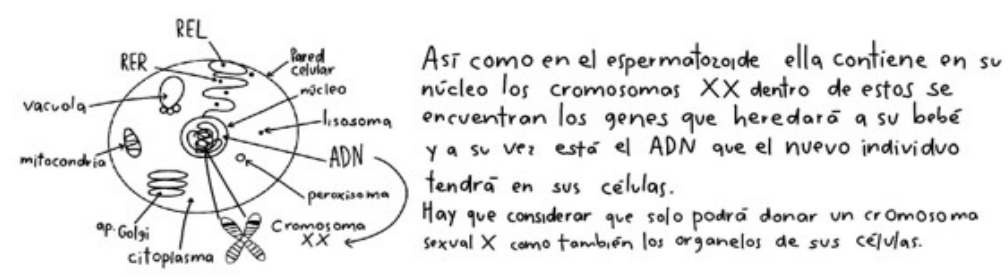

b)

Figura 4. Alumno del G3: Representación de los gametos, espermatozoide (a) y óvulo (b), en nivel 5. Describe la información genética en distintos niveles de organización: nucleótidos, cadena de ADN, gen, cromosomas sexuales y autosomas.

Nivel 5. Además de lo descrito en los niveles 3 y 4, en óvulo y espermatozoide representa nucleótidos y bases nitrogenadas; describe la aportación de información genética de los padres por el proceso de meiosis; menciona que los gametos son haploides (aunque llega a dibujarlos 
con cromosomas duplicados) y tienen un cromosoma sexual además de otros cromosomas no sexuales; explicita que hay genes (o alelos) dominantes y recesivos para cada característica (figura 5).
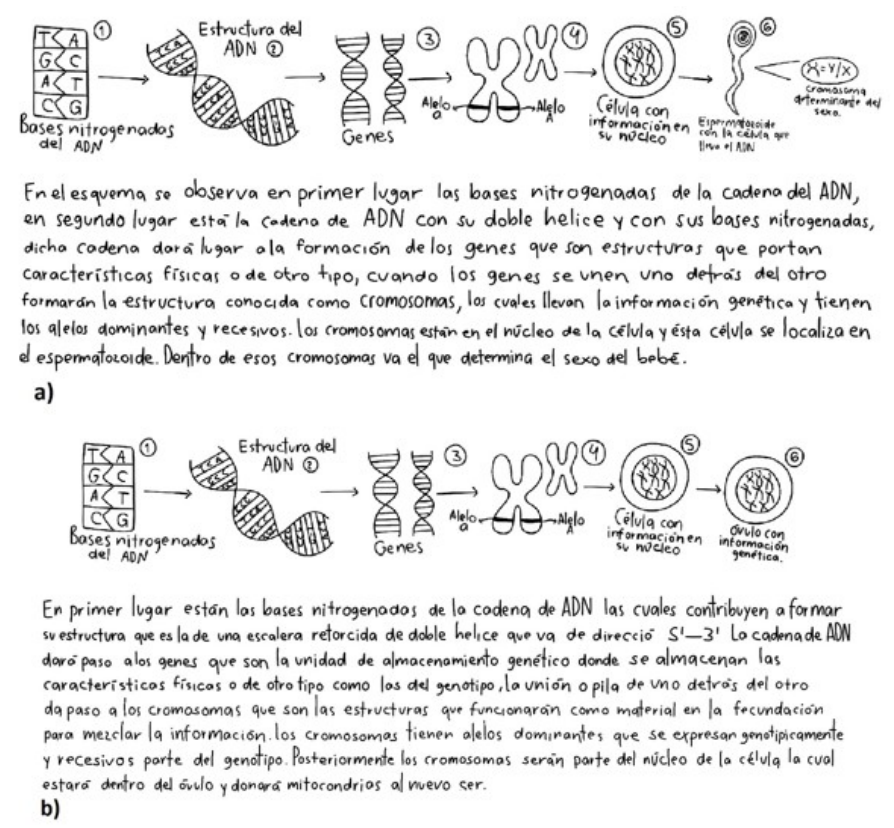

Figura 5. Alumno de G3: Representación de los gametos, espermatozoide (a) y óvulo (b), en nivel 4. La información genética se presenta como doble cadena de ADN y cromosomas; señala que los cromosomas de cada padre se unen para heredarlos al bebé.

\section{Resultados}

Los resultados de los cuestionarios calificados con los niveles descritos para cada ítem, muestran diferencias significativas entre los tres grupos (ANOVA - Statistical Package for the Social Sciences [SPSS]), con valores de F entre 7.03 (item 2) y 56.66 (ítem 11), p<0.05. Los valores por ítem se muestran en la tabla 5 .

Tabla 5. Análisis de varianza de los resultados por grupo para cada ítem.

\begin{tabular}{|r|r|r|r|r|r|r|r|r|}
\hline Ítem & \multicolumn{2}{|c|}{ G1 } & \multicolumn{2}{|c|}{ G2 } & \multicolumn{2}{|c|}{ G3 } & F & Sig. \\
\hline 1 & Media & \multicolumn{1}{c|}{ DS } & \multicolumn{1}{c|}{ Media } & \multicolumn{1}{c|}{ DS } & Media & \multicolumn{1}{l|}{ DS } & & \\
\hline 2 & 2.6 & 0.643 & 3.17 & 0.642 & 3.15 & 0.769 & 13.319 & 0 \\
\hline 3 & 3.38 & 0.846 & 3.13 & 0.676 & 3.7 & 0.976 & 7.029 & 0.001 \\
\hline 4 & 2.6 & 1.108 & 2.7 & 1.319 & 3.5 & 0.749 & 13.439 & 0 \\
\hline 5 & 2.4 & 1.167 & 2.77 & 1.198 & 3.5 & 0.749 & 18.067 & 0 \\
\hline 6 & 2.8 & 0.84 & 2.35 & 1.022 & 3.89 & 0.897 & 47.159 & 0 \\
\hline 7 & 2.2 & 1.07 & 2.32 & 1 & 3.35 & 0.813 & 27.527 & 0 \\
\hline 8 & 2.2 & 1.102 & 2.95 & 1.431 & 3.48 & 0.965 & 18.856 & 0 \\
\hline 9 & 2.13 & 1.016 & 2.67 & 1.537 & 3.53 & 0.728 & 24.535 & 0 \\
\hline 10 & 2.62 & 1.195 & 2.53 & 1.255 & 3.65 & 1.102 & 17.705 & 0 \\
\hline 11 & 3.08 & 0.381 & 2.98 & 1.017 & 3.76 & 0.766 & 19.232 & 0 \\
\hline 12 & 2.52 & 0.676 & 2.63 & 1.073 & 4.08 & 0.966 & 56.658 & 0 \\
\hline
\end{tabular}


Tabla 5. Continuación

\begin{tabular}{|r|r|r|r|r|r|r|r|r|}
\hline Ítem & \multicolumn{2}{|c|}{ G1 } & \multicolumn{2}{|c|}{ G2 } & \multicolumn{2}{|c|}{ G3 } & \multicolumn{1}{l|}{ F } & Sig. \\
\hline 1 & Media & \multicolumn{1}{|c|}{ DS } & Media & \multicolumn{1}{c|}{ DS } & Media & \multicolumn{1}{l|}{ DS } & \\
\hline 2 & 2.6 & 0.643 & 3.17 & 0.642 & 3.15 & 0.769 & 13.319 & 0 \\
\hline 3 & 3.38 & 0.846 & 3.13 & 0.676 & 3.7 & 0.976 & 7.029 & 0.001 \\
\hline 4 & 2.6 & 1.108 & 2.7 & 1.319 & 3.5 & 0.749 & 13.439 & 0 \\
\hline 5 & 2.4 & 1.167 & 2.77 & 1.198 & 3.5 & 0.749 & 18.067 & 0 \\
\hline 6 & 2.8 & 0.84 & 2.35 & 1.022 & 3.89 & 0.897 & 47.159 & 0 \\
\hline 7 & 2.2 & 1.07 & 2.32 & 1 & 3.35 & 0.813 & 27.527 & 0 \\
\hline 8 & 2.2 & 1.102 & 2.95 & 1.431 & 3.48 & 0.965 & 18.856 & 0 \\
\hline 9 & 2.13 & 1.016 & 2.67 & 1.537 & 3.53 & 0.728 & 24.535 & 0 \\
\hline 10 & 3.62 & 1.195 & 2.53 & 1.255 & 3.65 & 1.102 & 17.705 & 0 \\
\hline 11 & 2.52 & 0.676 & 2.63 & 1.073 & 4.08 & 0.966 & 56.658 & 0 \\
\hline 12 & 2.95 & 0.811 & 2.37 & 0.938 & 3.5 & 0.789 & 28.138 & 0 \\
\hline 13 & 3.08 & 0.381 & 3.28 & 1.027 & 4.08 & 0.535 & 35.942 & 0 \\
\hline 14 & 3.27 & 0.936 & 2.7 & 0.926 & 3.76 & 0.86 & 21.382 & 0 \\
\hline 15 & 3.32 & 0.725 & 3.12 & 0.761 & 3.64 & 0.694 & 8.255 & 0 \\
\hline 16 & 2.62 & 0.761 & 3.05 & 0.429 & 3.65 & 0.69 & 41.09 & 0 \\
\hline 17 & 2.47 & 0.892 & 2.28 & 0.94 & 3.41 & 0.679 & 32.994 & 0 \\
\hline 18 & 3.33 & 1.13 & 3.87 & 0.623 & 4.74 & 0.474 & 51.961 & 0 \\
\hline
\end{tabular}

De acuerdo con la tabla 5, el G3 alcanzó los valores de medias más altos en todos los casos. La mayor distancia entre las medias ( $\mathrm{m}=4.08 \sigma=0.966$ para $\mathrm{G} 3, \mathrm{~m}=2.63 \sigma=1.073$ para $\mathrm{G} 2$ y $\mathrm{m}$ $=2.52 \sigma=0.676$ para G1) se presentó en el ítem $11(\mathrm{~F}=56.66)$, donde los alumnos del G3 logran identificar que la herencia del tipo sanguíneo es resultado del mecanismo de alelos múltiples y explican por qué la descendencia puede presentar un tipo de sangre diferente al de los padres, mientras que los estudiantes de G2 y G1 no describieron ningún mecanismo o solo hacían referencia a genes dominantes y recesivos. La menor diferencia corresponde al ítem 2 $(\mathrm{m}=3.38 \sigma=0.846$ para $\mathrm{G} 1, \mathrm{~m}=3.13 \sigma=0.676$ para $\mathrm{G} 2$ y $\mathrm{m}=3.7 \sigma=0.976$ para $\mathrm{G} 3 ; \mathrm{F}=$ 7.03), en el que los alumnos, de manera general, identificaron que la información que los padres heredan está en los gametos, pero sin explicar el proceso. Solo en el ítem 1, el G3 obtuvo una media ligeramente menor que el G2 ( $\mathrm{m}=3.15 \sigma=0.769$, para $\mathrm{G} 3 ; \mathrm{m}=3.17$ $\sigma=0.642$, para $\mathrm{G} 2 ; \mathrm{m}=2.6 \sigma=0.643$ para $\mathrm{G} 1 ; \mathrm{F}=13.32$ ), lo que refleja que los estudiantes de ambos grupos alcanzan un nivel semejante, al describir que un bebé expresa ciertas características de sus padres porque cada uno de ellos aporta información genética que se combina, y mencionan o explican algún mecanismo de herencia. El G1 respondió en forma menos precisa, mencionando términos sin explicarlos.

En el ítem 18, el G3 presentó la media más alta $(\mathrm{m}=4.74 \sigma=0.474)$, debido a que los alumnos representaron gráficamente las distintas estructuras en que se organiza la información genética y distinguieron entre células sexuales y somáticas, mientras los estudiantes del G2 y G1, si bien, representaron gráficamente las estructuras o las células, no las ubicaron correctamente.

Para analizar más integralmente los logros conceptuales y representacionales de los alumnos, los resultados se han organizado en cuatro subtemas que cubren los aspectos marcados en las secuencias y el cuestionario. Los subtemas y sus ítems correspondientes son: Gametos (ítems 2, 3, 4, 7); Células somáticas (ítems 5, 6, 8, 9); Mecanismos de herencia y expresión de 
características $(1,7,8,10,11,12,14,17)$; Alteraciones genéticas (ítems 13, 14, 15, 16). Para cada subtema se determinó la media alcanzada por ítem y el nivel alcanzado en la rúbrica. Esto permitió determinar, para cada grupo, el valor de la media por subtema y el porcentaje de alumnos correspondiente. Los alumnos se ubicaron en dos intervalos: los que alcanzaron los niveles 0 a 2 y los que alcanzaron los niveles 3 a 5 en la rúbrica.

En la tabla 6 se presentan los datos que muestran que los alumnos de G3 obtienen las medias más altas y tiene el porcentaje mayor de alumnos en los niveles más altos (91\% - 97\%). Esto significa que esos alumnos establecieron más relaciones (parciales, totales o complejas) entre los elementos conceptuales y representacionales de cada subtema y alcanzaron mayor Integración de Conocimiento que, como se mencionó, implica tener la habilidad de generar ideas relevantes que puedan relacionarse para elaborar mejores explicaciones. En G2 y G1 también hay alumnos con niveles altos, pero en menor porcentaje.

Tabla 6. Nivel de logro conceptual alcanzado por los alumnos en cada subtema.

\begin{tabular}{|l|l|l|l|l|l|l|l|l|l|}
\hline & \multicolumn{3}{|c|}{ G1 } & \multicolumn{3}{c|}{ G2 } & \multicolumn{3}{c|}{ G3 } \\
\hline Subtema & Media & $\begin{array}{c}\text { \% } \\
\text { Niveles } \\
0-2\end{array}$ & $\begin{array}{c}\text { Niveles } \\
3-5\end{array}$ & Media & $\begin{array}{c}\% \\
\text { Niveles } \\
0-2\end{array}$ & $\begin{array}{c}\% \\
\text { Niveles } \\
3-5\end{array}$ & Media & $\begin{array}{c}\% \\
\text { Niveles } \\
0-2\end{array}$ & $\begin{array}{c}\text { Niveles } \\
3-5\end{array}$ \\
\hline Gametos & 2.6 & 37 & 63 & 2.8 & 28 & 72 & 3.5 & 9 & 91 \\
\hline $\begin{array}{l}\text { Células } \\
\text { somáticas }\end{array}$ & 2.6 & 43 & 57 & 2.7 & 36 & 64 & 3.7 & 7 & 93 \\
\hline $\begin{array}{l}\text { Mecanismos } \\
\text { de herencia }\end{array}$ & 2.5 & 36 & 64 & 2.7 & 34 & 68 & 3.5 & 9 & 91 \\
\hline $\begin{array}{l}\text { Alteraciones } \\
\text { genéticas }\end{array}$ & 3 & 16 & 84 & 3 & 18 & 82 & 3.7 & 3 & 97 \\
\hline
\end{tabular}

\section{Análisis y discusión}

Los resultados muestran que los estudiantes del G3, quienes estuvieron en un proceso de enseñanza más enriquecido con diversas representaciones externas y donde hubo mayor variedad en las formas de organización del grupo y dinámicas de trabajo, alcanzan niveles de respuesta mayores que los otros dos grupos, de los cuales resulta menos favorecido el que tuvo un proceso de enseñanza más tradicional (G1).

Una comparación de las respuestas de los alumnos, evidencia el tipo de conexiones que establecen en cada subtema (gametos, células somáticas, mecanismos de herencia, alteraciones genéticas) y cómo esto, les permite alcanzar mayor comprensión e integración. Un ejemplo de ello es el subtema de Gametos. Las figuras 1 a 5 sirven para ilustrar la comprensión del subtema de acuerdo con los niveles de la rúbrica que alcanzan los alumnos.

Como puede notarse en las representaciones gráficas, descripciones y explicaciones del nivel 3 al nivel 5 (ver figuras 3, 4 y 5) los alumnos logran mayor articulación e integración de sus ideas al representar la información genética de los gametos en los distintos niveles de organización, reconocer que óvulo y espermatozoide son células especializadas para la reproducción, que se formaron por meiosis, que tienen la mitad de la carga genética del individuo y que, al ser células haploides, presentan un cromosoma homólogo de cada par y no llevan solo un cromosoma sexual.

Para el resto de los subtemas también fue posible identificar el avance de los alumnos, lo que se describe en los siguientes párrafos, centrándose en los logros a partir del nivel 3 al 5 , puesto 
que, los niveles 1 y 2 presentan respuestas desvinculadas, poco precisas o sin relación entre ellas.

Para el subtema Células somáticas, los resultados de G3 también muestran diferencias relevantes en el porcentaje alcanzado en los niveles 3 a 5 , pues se obtuvo $93 \%$, mientras que G2, 64\% y G1, 57\%. Conforme los alumnos se ubican en el nivel más alto, distinguen dos tipos de células, los gametos (haploides, con 23 cromosomas) y las células somáticas (diploides, con 23 pares de cromosomas), representan o describen la información genética que tienen, reconocen que se especializan mediante la activación o inactivación de genes, representan correctamente el genotipo de células haploides y diploides para un caracter que se expresa por dominancia-recesividad.

En Mecanismos de herencia, G3 alcanzó un porcentaje de 91\% en niveles 3 a 5, G2 de 68\% y G1 de 64\%, lo que, una vez más, evidencia la distancia en el logro entre los tres grupos. El avance de los alumnos se aprecia cuando distinguen que: existen diferentes mecanismos; hacen uso de ellos para describir las probabilidades de herencia de un caracter; vinculan el origen de los gametos con la variedad en la información que tienen; explican la independencia de herencia de caracteres, como el ejemplo del tipo sanguíneo.

En el subtema Alteraciones genéticas los tres grupos tuvieron los porcentajes más altos: G3 con $97 \%$, G1 con $84 \%$ y G2 con $82 \%$. Distinguen que existen distintos tipos de alteraciones, que éstas se clasifican por el nivel en el que se modifica la información genética (genes, cromosomas, $\mathrm{ADN}$ ), y pueden representar gráficamente el tipo de alteración que describen. En el ejemplo de Síndrome de Down, ubican en qué nivel ocurre y qué lo puede causar.

Al considerar los cuatro subtemas, podemos concluir que más del $50 \%$ de los alumnos de los tres grupos alcanzaron un nivel de logro conceptual suficiente para establecer relaciones entre los temas abordados, lo que refiere que la organización y trayectoria conceptual propuesta fue de utilidad para comprender e interpretar el tema de la forma esperada para este nivel educativo. Sin embargo, también destaca que, el uso de mayor diversidad y cantidad de representaciones externas influyó en que los alumnos del G3 integraran y comprendieran mejor todos los aspectos conceptuales abordados en las actividades de la secuencia, como lo muestran los porcentajes de este grupo en los cuatro subtemas, que siempre fue mayor al $91 \%$.

En síntesis, se puede establecer que los distintos formatos representacionales usados por los alumnos del G3, aunado a la diversidad de tareas y organización de trabajo que realizaron, mejoraron la comprensión de los temas y facilitaron la resolución del cuestionario, ya que las respuestas escritas y las representaciones gráficas que generaron alcanzaron niveles de respuesta más altos. Los alumnos del G2, que contaron con un uso intermedio de representaciones externas y donde las dinámicas de trabajo implicaban menor interacción con sus compañeros y con el docente, también muestran su influencia, pues los recursos gráficos y animaciones que utilizaron para comprender los niveles de organización de la información genética fueron útiles para reconocerlos en el cuestionario, los esquemas usados para analizar el ciclo celular ayudaron a reconocer que mitosis y meiosis son procesos diferentes, pero no establecieron conexiones entre meiosis y la variabilidad genética. Los alumnos del G1, obtuvieron resultados cercanos al G2 en ítems que demandaban respuestas de tipo escrito, mientras que evidenciaron logros menores en sus representaciones gráficas; en los casos donde se implicaban los cuadros de Punnett, los resultados mostraron que, al igual que en G2, los alumnos identificaron el genotipo y fenotipo, pero no les fue posible establecer conexiones entre esta información y la que se requería para responder otros ítems. 


\section{Consideraciones Finales}

Al comparar los logros conceptuales de los alumnos que trabajaron el tema de genética en diferentes condiciones respecto al uso de representaciones externas y dinámicas de trabajo en el grupo, se fortalece la postura de diversos autores, que destacan la influencia de las representaciones para comprender, interpretar, construir e integrar los conceptos. Así, los alumnos que emplearon más representaciones externas, en un proceso didáctico que les ayudó a reconocer sus características, posibilidades de uso y la forma en que podían usarlas para reinterpretar sus ideas, mediado por alternativas para trabajar con sus compañeros y el profesor, tuvieron mejores oportunidades para disminuir las dificultades que el tratamiento del tema conlleva, es decir, lograron una mejor comprensión de las estructuras y niveles de organización de la información genética y de los procesos y mecanismos de herencia, lo que evidencia que pueden establecer conexiones entre los diferentes modelos conceptuales señalados por Stewart, Cartier y Passmore (2005).

Los resultados obtenidos muestran que, en general, si el docente dispone de mayor uso y diversidad de representaciones externas, genera condiciones para visualizar, interpretar, comparar y conectar, explícitamente, aquellos aspectos representacionales que apoyan la comprensión de la jerarquía entre los distintos niveles de organización de la información genética y, la posibilidad de transitar entre los niveles representacionales macro y microscópico, así como la forma en que dicha información participa en los diferentes procesos y mecanismos de herencia y expresión de caracteres, los alumnos mejorarán su comprensión.

Si bien, en los tres procesos de intervención, los alumnos alcanzaron logros conceptuales en ciertos temas, como el caso de los mecanismos de herencia y las alteraciones genéticas, los estudiantes que usaron menos recursos representacionales y mantuvieron dinámicas de trabajo más individuales y con menos interacción con el grupo y el profesor, mostraron desventajas, lo que se refleja en incongruencias y errores en algunas de sus respuestas, o bien, resolvieron problemas de herencia mecánicamente, sin comprender los mecanismos implicados, lo que refleja un determinismo entre genotipo y fenotipo, dificultad señalada por autores como Clément y Castéra (2013).

Finalmente, este trabajo constituye una descripción aún muy general de las posibles ventajas de las actividades en aula con el apoyo de múltiples representaciones externas. Un análisis más fino, sobre qué representaciones presentan más ventajas, qué conjunto de representaciones y su orden de presentación sería más conveniente, o qué competencias representacionales se requiere desarrollar para lograr una mejor comprensión de temas complejos, son algunas de las interrogantes a investigar para contribuir al establecimiento de apoyos que favorezcan un mayor logro conceptual.

\section{Agradecimientos}

Los datos que se reportan en esta investigación se derivaron del proyecto "Procesos de transformación de las representaciones científicas en los estudiantes del bachillerato bajo un entorno multi-representacional apoyado con tecnologías digitales", financiado por Conacyt con clave: 238712. Los autores agradecen la colaboración de los profesores y estudiantes que participaron en dicho proyecto.

\section{Referencias}

Banet, E., Ayuso, E. (2000) Teaching Genetics at Secondary School: A Strategy for Teaching about the Location of Inheritance Information. Science Education 84, 313-351.

Caballero, M. (2008) Algunas ideas del alumnado de secundaria sobre conceptos básicos de genética. Enseñanza de las Ciencias 26(2), 227-243. 
Clément, P., Castéra J. (2013) Multiple Representations of Human Genetics in Biology Textbooks. En D.F. Treagust y C-Y. Tsui (Eds.), Multiple Representations in Biological Education (pp. 147-164). Dordrech: Springer.

Diez de Tancredi, D., Caballero, C. (2004) Representaciones externas de los conceptos biológicos de gen y cromosoma. Su aprendizaje significativo. Revista de Investigación 56, 91-121.

diSessa, A. (2002) Why "conceptual ecology" Is a good idea. En M. Limón y L. Mason (Eds.), Reconsidering Conceptual Change: Issues in Theory and Practice (pp. 29-60). Dordrecht: Kluwer Academic Publishers.

Eilam, B. (2013) Possible Constraints of Visualization in Biology: Challenges in Learning with Multiple Representations. En D. F. Treagust y C-Y. Tsui (Eds.), Multiple Representations in Biological Education (pp.147-164). Dordrech: Springer.

Escuela Nacional Preparatoria [ENP]. (1996) Programa de estudios de la asignatura de Biología V. Universidad Nacional Autónoma de México. Distrito Federal, México. Fecha de consulta: 15-enero-2018. Disponible en: <http://dgenp.unam.mx/planesdeestudio/sexto/1613.pdf>

Figini, E., De Micheli, A. (2005) La enseñanza de la genética en el nivel medio y la educación polimodal: contenidos conceptuales en las actividades de los libros de texto. Enseñanza de las Ciencias num. extra, 1-5.

Flores, F. (2004). El cambio conceptual: interpretaciones, transformaciones y perspectivas. Educación Quimica, de aniversario 15(3), 60-73.

Flores-Camacho, F., García-Rivera, B., Báez-Islas, A., Gallegos-Cázares, L. (2017) Diseño y validación de un instrumento para analizar las representaciones externas de estudiantes de bachillerato sobre genética. Revista Iberoamericana de Evaluación Educativa 10(2), 151 169.

Freidenreich, H., Duncan, R., Shea, N. (2011) Exploring middle school students' understanding of three conceptual models in genetics. International Journal of Science Education 33(17), 2323-2349. doi:10.1080/09500693.2010.536997

Garófalo, S., Chemes, L., Alonso, M. (2016) Propuesta didáctica de enseñanza con simulaciones para estudiantes del profesorado en Ciencias Biológicas. Revista Eureka sobre Enseñanza y Divulgación de las Ciencias 13(2), 359-372.

Garvin, W., Stefani, L. (1993) Genetics-genetic disorder and diagnosis: a role-play exercise. Journal of Biological Education 27(l), 51-57. doi:10.1080/00219266.1993.9655304

Gilbert, J. (2008) Visualization: an emergent field of practice and enquiry in science education. En J. K., Gilbert, M. Reiner y M. Nakhleh (Eds.), Visualization: Theory and practice in science education (pp.3-24). Amsterdam: Springer.

Gericke, N., Wahlberg, S. (2013) Clusters of concepts in molecular genetics: A study of Swedish upper secondary science students understanding. Journal of biological education 47(2), 73-83. doi:10.1080/00219266.2012.716785

Horwitz, P., Neumann, E., Schwartz, J. (1996) Teaching science at multiple space-time scales. Communications of the ACM 39(8), 100-102.

Ibáñez, M. Martínez Aznar, M. (2005) Solving problems in genetics (II): Conceptual restructuring. International Journal of Science Education 27(12), 1495-1519. 
Iñiguez, J. (2005) La enseñanza de la genética, una propuesta didáctica para la educación secundaria obligatoria desde una perspectiva constructivista. Tesis doctoral. Universidad de Barcelona, Barcelona.

Kapteijn, M. (1990) The function of organizational levels in biology for describing and planning biology education. En P. L. Lijnse, P. Licht, W. de Vos y A. J. Vaarlo (Eds.), Relating macroscopic phenomena to microscopic particles (pp. 139-150). Utrecht, The Netherlands: CD-Press.

Knippels, M. (2002) Coping with the abstract and complex nature of genetics in biology education. The yoyo learning and teaching strategy. Utrecht, Netherlands: CD- $\beta$ Press. Fecha de consulta: $11-$ oct-2018.

Disponible

en:

<https://dspace.library.uu.nl/bitstream/handle/1874/219/full.pdf >

Kozma, R., Russell, J. (2005) Students becoming chemists: developing representational competence. En J. Gilbert (Ed.), Visualization in Science Education (pp. 121-146). Amsterdam: Springer.

Lee, H-S., Liu, O, L., Linn, M. (2011) Validating measurement of knowledge integration in science using multiple-choice and explanation items. Applied Measurement in Education 24(2), 115-136. doi:10.1080/08957347.2011.554604

Lewis, J., Leach J., Wood-Robinson, C. (2000) All in the genes? Young people's understanding of the nature of genes. Journal of Biological Education 34(2), 74-79. doi:10.1080/00219266.2000.9655689

Marbach-Ad, G., Stavy, R. (2000) Student's cellular and molecular explanations of genetic phenomena. Journal of Biological Education 34(4), 200-210. doi:10.1080/00219266.2000.9655718

Martí, E., Pozo, J. (2000) Beyond mental representations: The acquisition of external systems of representation. Infancia y Aprendizaje 23(90), 11-30. doi:10.1174/021037000760087946

Organización de las Naciones Unidas para la Educación, la Ciencia y la Cultura [UNESCO]. (2000) La ciencia para el siglo XXI. Un nuevo compromiso. UNESCO: París.

Prain, V., Tytler, R. (2012) Learning through constructing representation in science: A framework or representational construction affordances. International Journal of Science Education 34(17), 2751-2773. doi:10.1080/09500693.2011.626462

Prain, V., Tytler, R. (2013). Representing and learning in science. En R. Tytler, V. Prain, P. Hubber y B. Waldrip (Eds.), Constructing representations to learn in science (pp. 1-14). Rotterdam: Sense Publishers.

Rotbain, Y., Stavy, R., Marbach-Ad, G. (2008) The Effect of Different Molecular Models on High School Students' Conceptions of Molecular Genetics. Science Education Review 7(2), 54-69.

Schneider, E., Della, L., Bologna, A., Benetti, T., Andrade, A., Meglhioratti, A. (2011) Conceitos de gene: construção histórico-epistemológica e percepções de professores do ensino superior. Investigações em Ensino de Ciências 16(2), 201-222.

Schnotz, W., Bannert, M. (2003) Construction and interference in learning from multiple representation. Learning and Instruction 13, 141-156. 
Schonborn, K., Bogeholz, S. (2013) Experts' Views on Translation Across Multiple External Representations in Acquiring Biological Knowledge About Ecology, Genetics, and Evolution. En D. F. Treagust y C-Y. Tsui (Eds.), Multiple Representations in Biological Education (pp.147-164). Dordrecht: Springer.

Stewart, J., Cartier, J., Passmore, C. (2005) Developing understanding through model-based inquiry. En M. S. Donovan, y J. D. Bransford (Eds.), How students learn: History, mathematics, and science in the classroom (pp. 515-565). Washington, DC: The National Academic Press.

Tsui, C-Y., Treagust, D. (2013) Secondary Students' Understanding of Genetics Using BioLogica: Two Case Studies. En D. Treagust y C-Y. Tsui (Eds.), Multiple Representations in Biological Education (pp. 269-292). Dordrecht: Springer

Venville, G., Donovan, J. (2007) Developing year 2 students' theory of biology with concepts of the gene and DNA. International Journal of Science Education 29, 1111-1131. doi:10.1080/09500690600931079

Wilson, M. (2005) Constructing measures: An item response modeling approach. Mahwah, NJ: Lawrence Erlbaum Associates.

Wu, H., Puntambekar, S. (2012) Pedagogical affordances of multiple external representations in scientific processes. Journal of Science Education and Technology 21(6), 754-767. doi:10.1007/s10956-011-9363-7 